\title{
Adult Caregivers in the United States: Characteristics and Differences in Well-being, by Caregiver Age and Caregiving Status
}

Lynda A. Anderson, PhD; Valerie J. Edwards, PhD; William S. Pearson, PhD; Ronda C. Talley, $\mathrm{PhD}, \mathrm{MPH}$; Lisa C. McGuire, PhD; Elena M. Andresen, PhD

Suggested citation for this article: Anderson LA, Edwards VJ, Pearson WS, Talley RC, McGuire LC, Andresen EM. Adult Caregivers in the United States: Characteristics and Differences in Well-being, by Caregiver Age and Caregiving Status. Prev Chronic Dis 2013;10:130090. DOI: http://dx.doi.org/10.5888/pcd10.130090 捣 .

PEER REVIEWED

\section{Abstract}

We examined the characteristics of adults providing regular care or assistance to friends or family members who have health problems, long-term illnesses, or disabilities (ie, caregivers). We used data from the 2009 Behavioral Risk Factor Surveillance System (BRFSS) to examine caregiver characteristics, by age and caregiving status, and compare these characteristics with those of noncaregivers. Approximately $24.7 \%$ (95\% confidence interval, 24.4\%-25.0\%) of respondents were caregivers. Compared with younger caregivers, older caregivers reported more fair or poor health and physical distress but more satisfaction with life and lower mental distress. Understanding the characteristics of caregivers can help enhance strategies that support their role in providing long-term care.

\section{Objective}

In 2007, Talley and Crews framed caregiving as a public health issue and argued for its inclusion in state-level surveillance to obtain data about adult caregivers (1). Subsequently, a caregiving question was added to the 2009 Behavioral Risk Factor Surveillance System (BRFSS) survey. Respondents were asked whether they provided regular care or assistance to friends or family members who have health problems, long-term illnesses, or disabilities during the past month. The objective of this study was to examine the demographic characteristics of caregivers, compare caregivers with noncaregivers, and compare younger (aged 18-64) and older (aged $\geq 65$ ) caregivers on measures of well-being.

\section{Methods}

The BRFSS is an annual, state-based telephone survey (2). Data are from a representative sample of noninstitutionalized people aged 18 years or older from 50 states, the District of Columbia, and 2 US territories. Responses are weighted to the estimated population in states or territories. The median cooperation rate for the 2009 survey was 75.0\%, and the median Council of American Survey Research Organizations response rate was 52.5\%. A complete description of 2009 BRFSS procedures and definitions of response rates are available at www.cdc.gov/brfss/technical_infodata/surveydata/2009.htm.

Respondents were classified as caregivers if they responded yes to the following question added to the 2009 BRFSS core: "People may provide regular care or assistance to a friend or family member who has a health problem, long-term illness, or disability. During the past month, did you provide any such care or assistance to a friend or family member?" Estimates were calculated for prevalence of caregiving by demographic measures (age, sex, race/ethnicity, education, marital status, and employment status) using pairwise deletion. Ninety-five percent confidence intervals (CIs) were provided for each estimate, and SPSS software version 20 (IBM Corp, Armonk, New York) was used to account for the BRFSS's complex sample design. 
Respondents were classified as having frequent physical distress if they reported they had experienced 14 or more days in the past month when their physical health interfered with their daily activities. Respondents were classified as having frequent mental distress if they reported 14 or more days when their mental health interfered with daily activities. We compared caregivers and noncaregivers on self-reported, health-related quality of life, degree of life satisfaction, and availability of emotional support. Finally, we compared older caregivers with younger caregivers on these same health and well-being measures. We used the Rao-Scott adjusted $\chi^{2}$ statistic to determine the independence of all comparisons.

\section{Results}

Overall, 24.7\% (95\% CI, 24.4\%-25.0\%) of respondents to the 2009 BRFSS were classified as caregivers. Caregivers were significantly more likely to be 50 to 64 years of age than from other age groups, to be female than male, and to be non-Hispanic black than from other racial/ethnic groups (Table 1). Caregivers were significantly more likely to have some college education than to have a high school education or less or to be a college graduate; they were also significantly more likely to be married or part of an unmarried couple than to be divorced, separated, widowed, or never married (Table 1).

Comparing caregivers with noncaregivers, significantly more caregivers reported fair or poor self-rated health $(16.9 \%$ [95\% CI, 16.4\%-17.3\%] vs 15.8\% [95\% CI, 15.5\%-16.0\%]), more frequent physical distress (12.0\% [95\% CI, 11.6\%$12.4 \%$ ] vs $10.5 \%$ [ $95 \%$ CI, 10.3\%-10.7\%]), more frequent mental distress (14.3\% [95\% CI, 13.9\%-14.8\%] vs 9.4\% [95\% CI, 9.2\%-9.6\%]), and being dissatisfied or very dissatisfied with life (7.0\% [95\% CI, 6.7\%-7.4\%] vs 5.5\% [95\% CI, 5.3\% $-5.7 \%]$ ) than noncaregivers. Caregivers and noncaregivers did not differ, however, on the reported availability of social support (8.5\% [95\% CI, 8.1\%-8.9\%] vs 8.5\% [95\% CI, 8.2\%-8.7\%]).

Compared with younger caregivers, those aged 65 or older reported a higher prevalence of fair or poor self-rated health and more frequent physical distress compared with caregivers aged 18 to 64 years (Table 2). Caregiver age was not related to reports of availability of emotional support. Caregivers aged 65 or older reported lower prevalence of frequent mental distress and being dissatisfied or very dissatisfied with their life compared with caregivers aged 18 to 64 years (Table 2).

\section{Discussion}

Approximately one-quarter of respondents were classified as caregivers. Estimates of the prevalence of caregivers vary across studies because of differences in definitions, sampling, and the age of person receiving care (3). For example, the 2000 BRFSS found a prevalence of $16.4 \%$ (standard error, $0.2 \%$ ), but care was restricted to "a person aged 60 years or older" (4). Our higher prevalence may be due to elimination of the age restriction or other changes in the population and requires replication. We found that people classified as caregivers reported decrements in health-related quality of life compared with noncaregivers. We found that younger caregivers reported more mental distress compared with older caregivers. This finding is consistent with those of previous studies $(3,5)$.

The findings are subject to several limitations. Many factors may affect participation in telephone surveys and may influence our estimates of caregivers, such as their ability to participate in surveys, exclusion of institutionalized populations, and potential cultural differences about the meaning of providing care (6). We lacked data on the care recipient and the amount of time dedicated to care and type of caregiving activities. More detailed information about caregiving provision and activities is available from the BRFSS module being used in select states (5). Finally, data were collected in all 50 states, the District of Columbia, and 2 US territories and weighted to state-based population estimates.

Caregiving has gained national attention because family members have been and will continue to be the primary providers of care to those with illnesses and disabilities (7-9). Caregiving will likely increase as the US population ages (10). As a result, understanding the extent, characteristics, and effects of caregiving on health and well-being can enhance efforts to improve the quality of life of caregivers and inform national strategies such as evidence-based programs for caregivers (11) and care transitions (12).

\section{Acknowledgments}

This work was supported with funds provided by the Centers for Disease Control and Prevention's Division of Population Health.

\section{Author Information}

Corresponding Author: Lynda A. Anderson, PhD, Healthy Aging Program, Division of Population Health, Mailstop F78, 4770 Buford Hwy, NE, Atlanta, GA 30341. Telephone: 770-488-5998. E-mail: laao@cdc.gov. 
Author Affiliations: Valerie J. Edwards, William S. Pearson, Lisa C. McGuire, Centers for Disease Control and Prevention, Atlanta, Georgia; Ronda C. Talley, Western Kentucky University, Bowling Green, Kentucky; Elena M. Andresen, Oregon Health and Science University, Portland, Oregon.

\section{References}

1. Talley RC, Crews JE. Framing the public health of caregiving. Am J Public Health 2007;97(2):224-8. CrossRef 国 PubMed 圈

2. Centers for Disease Control and Prevention. BRFSS annual survey data. Survey data and documentation 2009. http://www.cdc.gov/brfss/technical_infodata/surveydata.htm. Accessed December 19, 2012.

3. Gitlin LN, Schulz R. Family caregiving of older adults. In: Prohaska TR, Anderson LA, Binstock RH, editors. Public health for an aging society. Baltimore (MD): Johns Hopkins University Press; 2012. p. 181-204.

4. McGuire LC, Okoro CA, Goins RT, Anderson LA. Characteristics of American Indian and Alaska Native adult caregivers, Behavioral Risk Factor Surveillance System, 2000. Ethn Dis 2008;18(4):477-82. PubMed 国

5. Neugaard BI, Andresen EM, McKune SL, Jamoom EW. Health-related quality of life in a national sample of caregivers: findings from the BRFSS. J Happiness Stud 2008;9:559-75. CrossRef

6. Pinquart M, Sörensen S. Ethnic differences in stressors, resources, and psychological outcomes of family caregiving: a meta-analysis. Gerontologist 2005;45(1):90-106. CrossRef 圈 PubMed 圈

7. Bouldin ED, Andresen E. Caregiving and health. In: Cavanaugh JC, Cavanaugh CK, editors. Aging in America, volume 2: physical and mental health. Santa Barbara (CA): Praeger; 2010. p. 81-99.

8. Carter R. Addressing the caregiving crisis. Prev Chronic Dis 2008;5(1):A02. http://www.cdc.gov/pcd/issues/2008/jan/o7_0162.htm. Accessed December 19, 2012. PubMed 图

9. Vos T, Flaxman AD, Naghavi M, Lozano R, Michaud C, Ezzati M, et al. Years lived with disability (YLDs) for 1160 sequelae of 289 diseases and injuries 1990-2010: a systematic analysis for the Global Burden of Disease Study 2010. Lancet 2012;380(9859):2163-96. CrossRef 图 PubMed 圈

10. Vincent GK, Velkoff VA. The next four decades, the older population in the United States: 2010 to 2050, population estimates and projections (no. P25-1138). US Census Bureau; 2010. http://www.census.gov/prod/2010pubs/p25-1138.pdf. Accessed June 25, 2013.

11. Translating innovation to impact: evidence-based interventions to support people with Alzheimer's disease and their caregivers at home and in their communities. Alliance for Aging Research; 2012. http://www.agingresearch.org/section/translating_innovation_to_impact. Accessed April 5, 2013.

12. About the Community-based Care Transitions Program. Centers for Medicare and Medicaid Services, Center for Medicare and Medicaid Innovation. http://innovation.cms.gov/initiatives/CCTP/?itemID=CMS1239313. Accessed April 5, 2013.

\section{Tables}

Table 1. Weighted Estimates of Caregivers, a by Selected Demographics, in the United States, District of Columbia, and 2 US Territories, Behavioral Risk Factor Surveillance System (BRFSS), 2009

\begin{tabular}{|l|c|c|}
\hline Characteristic & \% Weightedb Estimate (95\% Confidence Interval) & $\boldsymbol{P}$ Valuec \\
\hline Age, $\mathbf{y}$ & & \\
$18-34$ & $20.6(19.9-21.2)$ & \\
$35-49$ & $25.8(25.2-26.3)$ & $<.001$ \\
$50-64$ & $30.5(30.1-31.0)$ & \\
$\geq 65$ & $21.6(21.2-22.0)$ & \\
Sex & $22.0(21.6-22.5)$ & $<.001$ \\
Male & $27.2(26.9-27.6) \mid$ &
\end{tabular}




\begin{tabular}{|c|c|c|}
\hline Characteristic & $\%$ Weightedb Estimate ( $95 \%$ Confidence Interval) & $P$ Valuec \\
\hline \multicolumn{3}{|l|}{ Race/ethnicity } \\
\hline White, non-Hispanic & $24.8(24.6-25.1)$ & \multirow{4}{*}{$<.001$} \\
\hline Black, non-Hispanic & $28.6(27.5-29.7)$ & \\
\hline Other race or multiracial, non-Hispanic & $24.0(22.6-25.4)$ & \\
\hline Hispanic & $21.4(20.5-22.5)$ & \\
\hline \multicolumn{3}{|l|}{ Education } \\
\hline Less than high school & $20.4(19.4-21.4)$ & \multirow{4}{*}{$<.001$} \\
\hline High school graduate & $24.5(24.0-25.1)$ & \\
\hline Some college & $26.9(26.3-27.4)$ & \\
\hline College graduate & $24.5(24.0-24.9)$ & \\
\hline \multicolumn{3}{|l|}{ Marital status } \\
\hline Married/part of unmarried couple & $25.3(24.9-25.6)$ & \multirow{3}{*}{$<.001$} \\
\hline Divorced, separated, or widowed & $24.3(23.8-24.9)$ & \\
\hline Never married & $24.7(24.4-25.0)$ & \\
\hline \multicolumn{3}{|l|}{ Employment status } \\
\hline Employed for wages or self-employed & $24.6(24.2-25.0)$ & \multirow{3}{*}{.56} \\
\hline Not employed & $24.8(24.3-25.2)$ & \\
\hline Unable to work & $25.3(24.0-26.6)$ & \\
\hline
\end{tabular}

a Respondents were classified as caregivers if they answered yes to the following question: "People may provide regular care or assistance to a friend or family member who has a health problem, long-term illness, or disability. During the past month, did you provide any such care or assistance to a friend or family member?"

b Information about BRFSS weighting procedures can be found at http://www.cdc.gov/brfss/about/brfss_faq.htm\#15.

c $P$ value calculated using the Rao-Scott adjusted $X^{2}$ statistic.

Table 2. Weighted Estimates of Measures of Self-Reported Health and Wellbeing of Caregivers, by Age, Behavioral Risk Factor Surveillance System (BRFSS), 2009

\begin{tabular}{|l|r|r|r|}
\hline Measure & Prevalence Aged 18-64 (95\% & Prevalence Aged $\mathbf{2 6 5}(\mathbf{9 5 \%}$ & $\begin{array}{c}\boldsymbol{P} \\
\text { CI) }\end{array}$ \\
\hline Fair or poor self-rated health & $15.7(15.1-16.2)$ & $23.8(22.9-24.7)$ & $<.001$ \\
\hline Frequent mental distress & $15.3(14.8-15.9)$ & $8.6(8.0-9.2)$ & $<.001$ \\
\hline Frequent physical distress & $11.5(11.0-11.9)$ & $15.0(14.3-15.8)$ & $<.001$ \\
\hline Rarely/never get emotional support & $8.5(8.0-8.9)$ & $8.7(8.1-9.3)$ & .56 \\
\hline $\begin{array}{l}\text { Dissatisfied/very dissatisfied with } \\
\text { life }\end{array}$ & $7.6(7.2-8.0)$ & $3.8(3.4-4.2)$ & $<.001$ \\
\hline
\end{tabular}

Abbreviation: CI, confidence interval.

a $P$ value calculated using the Rao-Scott adjusted $X^{2}$ statistic.

The opinions expressed by authors contributing to this journal do not necessarily reflect the opinions of the U.S. Department of Health and Human Services, the Public Health Service, the Centers for Disease Control and Prevention, or the authors' affiliated institutions. 
Preventing Chronic Disease $\mid$ Adult Caregivers in the United States: Characteristics and D... Page 5 of 5

7. The RIS file format is a text file containing bibliographic citations. These files are best suited for import into bibliographic management applications such as EndNote 国, Reference Manager 国, andProCite 圈. A free trial download is available at each application's web site.

For Questions About This Article Contact pcdeditor@cdc.gov

Page last reviewed: August 15, 2013

Page last updated: August 15, 2013

Content source: National Center for Chronic Disease Prevention and Health Promotion

Centers for Disease Control and Prevention 1600 Clifton Rd. Atlanta, GA 30333, USA

80o-CDC-INFO (800-232-4636) TTY: (888) 232-6348 - Contact CDC-INFO

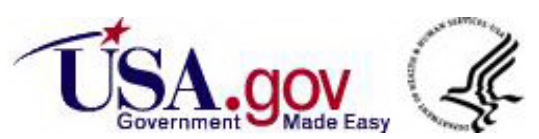

